\title{
A INVENÇÃO DEMOCRÁTICA BRASILEIRA E OS FANTASMAS TOTALITÁRIOS: O CASO DO JUDICIÁRIO APLICADO À OBRA DE CLAUDE LEFORT ${ }^{1}$
}

\author{
André Augusto Salvador Bezerra
}

\begin{abstract}
Resumo: As ideias de Claude Lefort são aplicáveis à realidade brasileira posterior à década de 1980. Trata-se do período coincidente a um amplo processo de invenção democrática, produto de mobilização social cujas bandeiras políticas transformaram-se em direitos previstos na Constituição de 1988. Por outro lado, a sociedade não logrou eliminar antigas estruturas ditatoriais do Estado e nem evitar o crescimento de um Poder Administrativo politicamente excludente, oriundo de ideias neoliberais. É o que ocorre no Judiciário brasileiro, chamado pela população para efetivar os direitos, mas ainda estruturado ditatorialmente e submetido a reformas que ampliam o Poder Administrativo a pretexto de garantir segurança jurídica. O presente trabalho pretende relacionar as ideias de Lefort ao atual contexto de fortalecimento de estruturas autoritárias no Judiciário em plena vigência de Constituição democrática.

Palavras-chaves: Claude Lefort - democracia - poder judiciário - constituição - autoritarismo.
\end{abstract}

\section{Introdução}

A conjuntura brasileira do presente início de século XXI revela a atualidade da obra política de Claude Lefort. Apesar das reflexões do autor terem sido formuladas com base no contexto europeu, mormente no período conhecido como Guerra Fria, o fato é que as suas ideias de democracia e totalitarismo aplicam-se à realidade do Brasil das últimas décadas.

No aludido período tem-se no país, de um lado, um amplo processo de mobilização social visando a previsão de novos direitos, muitos conquistados com a promulgação de Constituição de 1988; de outro lado, em plena vigência do atual sistema aparentemente democrático, subsistem estruturas autoritárias construídas pelo sistema ditatorial que vigorou até a década de 1980 e ultimamente ampliadas por reformas neoliberais.

Dentre os arcabouços autoritários que subsistem, destaca-se o Poder Judiciário. Inserido pelo legislador constituinte como vigoroso instrumento de efetivação dos direitos arduamente conquistados pela sociedade civil, a atividade jurisdicional brasileira, porém, ainda não foi democratizada, obstando-a a atingir seus fins constitucionais.

\footnotetext{
${ }^{1}$ Dossiê Claude Lefort: esse texto é parte do dossiê publicado a partir das comunicações realizadas no Colóquio Internacional Claude Lefort: a invenção democrática hoje, realizado na Universidade de São Paulo entre os dias 13 e 16 de outubro de 2015.

2 Juiz de Direito em São Paulo. Presidente do Conselho Executivo da Associação Juízes para a Democracia.
} 
A partir da dinâmica trabalhada por Lefort entre democracia e totalitarismo, o presente estudo focará o papel do Poder Judiciário no atual contexto político brasileiro. Para isso, será descrito, ainda que brevemente, o processo de redemocratização brasileira, via previsão de direitos, e a atuação do Judiciário desde este período; ao final, serão apontados os déficits democráticos da atividade jurisdicional que a tornam incapaz de barrar o avanço de ideias totalitárias crescentes nos últimos anos.

\section{A invenção democrática pós-ditadura}

O pensamento político de Claude Lefort centra-se na ideia de que a democracia não configura uma obra consolidada. Trata-se, pelo contrário, de processo incessante de demandas reivindicadas pela sociedade, que, pressionando o Estado, terminam por transformá-las em direitos.

A democracia consiste, assim, em um processo histórico que se reinventa constantemente (ROCHA, 2011, p. 50). Daí a expressão invenção democrática:

A democracia é invenção porque, longe de ser a mera conservação de direitos, é a criação ininterrupta de novos direitos, a subversão contínua do estabelecido, a restituição permanente do social e do político. Como criação de direitos, como reconhecimento das divisões internas e das diferenças constitutivas do social e do político, a democracia abre para a história no sentido forte da palavra (CHIAUI, 2011, p. 39).

Em tais termos, é possível dizer que a promulgação da Constituição Federal em 1988 simboliza uma invenção democrática brasileira. Com efeito, a abertura política (ainda que lenta) ocorrida nos anos finais da ditadura civil-militar pós-1964, possibilitou o recrudescimento dos movimentos sociais até então reprimidos e, consequentemente, uma desincorporação dos indivíduos (LEFORT, 2011, p. 150) do poder estatal.

A sociedade civil organizada ressurge carregando a bandeira dos direitos, não como um fim em si mesmo, mas como estratégia de consecução de suas demandas (DONNELLY, 2006, p. 71).

Com essas observações não se está a negar que a redação final do texto constitucional refletiu aquilo que Florestan Fernandes (1989, p. 47-48), então Deputado Constituinte, chamou de característica comum das constituições dos povos modernos: a tradução "ideológica e sociológica como as classes dominantes pretendem organizar a sociedade civil e o Estado". Como também percebido na época por Hebert de Souza (1989, p. 377), ao final, a Constituição de 1988 perdurou "[...] fundamentando a velha ordem do capital contra as aspirações sociais e políticas da democracia”. 
O fato, contudo, é que a Constituição previu uma série de direitos cuja índole eminentemente coletiva possibilita um caminhar do Estado brasileiro para além da igualdade formal burguesa. Os direitos sociais erigidos ao status constitucional como forma de proteção dos trabalhadores perante o capital e o direito dos indígenas à demarcação de terras a ser realizada em prejuízo da base do capitalismo (o instituto da propriedade individual) são dois casos, dentre tantos outros, que bem revelam as possibilidades de aprofundamento democrático pós-1988.

Tudo isso, como decorrência do fortalecimento do poder social, via mobilizações populares, cujo produto final "[...] não ataca o poder de frente, atinge-o obliquamente, por assim dizer, contornando-o [...]” (LEFORT, 2011, p. 80).

Ressalte-se que quando se fala em mobilizações, fala-se, primeiramente, da resistência no período do Estado Policial perpetrada por trabalhadores, sindicatos e "[...] diversas entidades e organizações que combatiam abertamente a ditadura e recorriam à desobediência civil como instrumento de desmoralização da ditadura e de sua desagregação" (FERNANDES, 1989, p. 51). Mas não é só. Fala-se também de mobilizações ocorridas nos próprios trabalhos da Assembleia Constituinte (1987-1988), que, prontamente, recebeu "11.989 sugestões da sociedade e dos constituintes cadastradas e processadas pela Constituinte, canalizando-as para as subcomissões a que se referiam seus temas" (MICHILES e outros., 1989, p. 64).

\section{Resistência à invenção democrática brasileira}

Os direitos instituídos em tal processo revelaram, assim, o quanto de "[...] reviravolta fazem na vida social” (LEFORT, 2011, p. 67) ${ }^{3}$. Por esse motivo, a resistência dos grupos hegemônicos às demandas populares na elaboração da Constituição: as bandeiras carregadas pelas populações historicamente subalternas tornaram-se verdadeiras inimigas a serem debeladas.

Tal resistência fez-se presente não apenas nos trabalhos do bloco parlamentar formado por representantes do capital e da velha ordem, conhecido como centrão (SOUZA, 1989, p. 377). Também se fez presente na propaganda hegemônica dos meios de comunicação empresariais, visando à formação de consenso para o não aprofundamento democrático via instituição de novos direitos.

Em pesquisa realizada sobre a cobertura veiculada, na época, pelos diários Jornal do Brasil, O Globo, O Estado de São Paulo e Folha de S. Paulo, Francisco Fonseca (2010, p.

\footnotetext{
3 Anota Marilena Chiaui (2011, p. 40) que: “descoberta a criação dos direitos, invenção contínua do social e do político, a democracia não pode, escreve Lefort, ser considerada uma criação burguesa, pois, muito pelo contrário, nascida da luta de classes, dos movimentos populares e operários, sempre foi considerada pela burguesia um escândalo e "um perigo maior do que o socialismo"'.
} 
23) percebeu que tais periódicos combateram uniformemente a ampliação de direitos sociais propostos durante a Assembleia Constituinte, como licença-maternidade, a licençapaternidade e a majoração do valor da hora-extra. Tais direitos, segundo o autor, eram tidos como catastróficos à produção (isto é, desestimulariam a produção e aumentariam o desemprego), inócuos (ou seja, não seriam respeitados pelo sistema econômico) e ameaçadores (isto é, colocariam em risco os demais direitos conquistados, como o mercado formal de trabalho).

Toda essa propaganda, embora tenha conseguido manter o sistema sob o controle dos grupos historicamente dominantes, não logrou impedir a instituição constitucional de direitos oriundos da mobilização social'. A Constituição Federal de 1988 é também produto do trabalho do poder social.

\section{A descoberta de um Judiciário autoritário}

Tais direitos, por outro lado, fizeram eclodir uma distância colossal entre a realidade das normas constitucionais e a realidade da vida da população brasileira, especialmente a dos mais pobres. Em tais termos, os cidadãos passaram a enxergar o Judiciário como importante instrumento para o encurtamento da aludida distância.

Foi sob esse contexto que adveio o fenômeno de explosão da litigiosidade: o Judiciário brasileiro tornou-se uma função de Estado abarrotada de processos.

Ressalve-se que tal fenômeno não é uma exclusividade brasileira, tendo origem européia, quando as normas do Welfare State também evidenciaram a distância entre a realidade normativa e a realidade da vida de considerável parcela da população. Lembra Boaventura de Sousa Santos (1986, p. 19) que, no final da década de 1960, a duração média de um processo civil na Itália, por exemplo, era de seis anos e cinco meses; essa situação agravou-se com a crise econômica mundial dos anos 1970, quando os recursos ficaram mais escassos para o chamado Estado de Bem-Estar Social.

No Brasil, o sistema posterior ao Golpe de 1964 não era propício para essa descoberta do Judiciário. O totalitarismo então implementado, tal como se espera de um regime dessa espécie, aboliu a autonomia da sociedade civil (LEFORT, 2011, p. 66), impedindo a instituição de direitos de natureza contra-hegemônica.

Daí que somente a partir do final da década de 1980 e início da década de 1990 a atividade jurisdicional passou a ser utilizada em massa pelos cidadãos: não por um acaso, sob a realidade das ambiciosas promessas normativas oriundas da mobilização social.

\footnotetext{
4 Tal circunstância, porém, deve ser vista a partir da histórica utilização dos direitos pelos grupos dominantes e dominados. É ínclito aos direitos ter um concomitante caráter excludente e inclusivo (BAXI, 2006, p. 167).
} 
Uma avalanche de processos foi repentinamente ajuizada. Evidenciou-se um antigo problema do Estado brasileiro: a desestruturação e a má gestão do Judiciário, politicamente organizado de forma semelhante ao período ditatorial anterior e incapaz de atender às demandas de uma sociedade democrática.

Para se ter uma ideia da estruturação democraticamente deficiente, a atividade funcional dos juízes continuou regida por diploma normativo imposto pelo ditador Ernesto Geisel. Trata-se da Lei Orgânica da Magistratura Nacional (LOMAN), em vigor desde o ano de 1979, sob o mesmo contexto que, poucos anos antes, havia levado ao conjunto de medidas autoritárias responsáveis até mesmo pelo fechamento do Congresso Nacional, conhecidas como Pacote de Abril.

Por sua vez, a superação normativa da ditadura representada pela promulgação da Constituição de 1988 não impediu que os componentes da cúpula do Judiciário brasileiro, o Supremo Tribunal Federal (STF), nomeados pelos militares pós-1964, perdurassem nas suas funções. Vale dizer, o país passou a ser regido por um documento constitucional democrático, interpretado, contudo, por ministros oriundos do totalitarismo anterior.

\section{A reforma do Judiciário e o controle externo}

A despeito de se tratar de uma função descoberta pelos cidadãos sob a democracia, o Judiciário brasileiro revelou-se prontamente uma função inadaptada a tal realidade.

Tem-se, então, mais uma característica da invenção democrática brasileira que se encontra com o pensamento político de Lefort. Como anota Chauí:

[...] Lefort descortina um aspecto essencial da democracia, qual seja, o de que ela carrega virtualmente representações sobre o social e o político que são atualizadas de fato pelo totalitarismo. Assim, o leitor que esperasse um contraponto transparente entre a "boa" democracia e o "mau" totalitarismo ficaria decepcionado. As contradições da democracia são indispensáveis para a compreensão do fenômeno totalitário [...]. (2011, p. 39)

Ficou claro que se fazia necessário adaptar a atividade jurisdicional à realidade democrática. Daí a reforma do Judiciário ter sido inserida à ordem do dia das discussões políticas.

Mencionadas discussões deram-se em dois níveis. Em um primeiro patamar, perante os próprios movimentos sociais, cuja mobilização permitiu a previsão de uma série de direitos por ocasião dos trabalhos da Assembleia Constituinte, mas não efetivados pelo Estado. A realidade estatal brasileira mostrou-se, ao longo dos anos de processo 
democrático, verdadeiro óbice ao aprofundamento dos direitos, no qual se inclui a atividade cotidiana do Judiciário, pouco transparente e autoritariamente organizada.

Mas os debates não ocorreram somente em tal patamar. As discussões também sucederam perante as elites do sistema econômico, prejudicadas pela desorganização de um Judiciário abarrotado e pela consequente morosidade no julgamento das causas.

Lembra Lefort (2011, p. 151) que o capitalismo se funda no "[...] culto burguês da ordem [...]". A ineficácia da atividade jurisdicional em apreciar os conflitos a ela levados sob a vigência democrática trouxe insegurança jurídica para as elites.

Foi sob esses dois níveis de discussão que se logrou a aprovação da Emenda Constitucional n. 45 de 2004. Tal documento previu o controle externo sobre o Judiciário pelo Conselho Nacional de Justiça (CNJ), dotado das funções de planejamento estratégico e gestão administrativa, além da fiscalização disciplinar e correcional sobre os magistrados. A mesma emenda estipulou a composição da entidade em 15 conselheiros: nove magistrados, dois membros do Ministério Público, dois advogados e dois cidadãos, indicados cada um por uma casa legislativa.

\section{O controle realizado: a prevalência da gestão sobre a democratização}

Pelas funções e pela composição é possível verificar que se trata de um controle eminentemente de gestão. A preocupação básica do CNJ é gerencial, buscando imprimir eficiência na administração da justiça, sem maiores preocupações quanto aos fundamentos da explosão da litigiosidade e às estruturas políticas do Judiciário construídas na ditadura e inadaptadas à democracia projetada constitucionalmente.

$\mathrm{O}$ resultado desse arcabouço revelou-se prontamente: no seu controle, o CNJ passou a se preocupar basicamente com o rápido julgamento das causas - e não com a aplicação de direitos -, partindo-se do pressuposto de que no Brasil há uma sociedade extremamente litigiosa, que leva a um Judiciário emperrado.

Essa preocupação com a rápida solução dos litígios exteriorizou-se basicamente pela imposição de metas de produtividade aos juízes. Isso, como se os membros do Judiciário fossem prestadores de serviços ao mercado consumidor, sendo o cidadão que tem seu direito violado um mero cliente.

O controle externo efetivado é, portanto, o controle defendido pelas elites do sistema econômico. O que se quer é a ordem nos julgamentos, via presteza, em respeito à economicamente almejada segurança jurídica.

Com a imposição de metas, parte-se do pressuposto de que o Judiciário é lento porque os respectivos membros não julgam as causas rapidamente como se deveria. Considera o Judiciário um poder de baixa produtividade. 
Apesar dos inúmeros problemas estruturais que o Judiciário brasileiro apresenta, é difícil sustentar que se trata de uma função de baixa produtividade. Somente no ano de 2013, quando a política de metas do CNJ encontrava-se a todo vapor, foram julgados pelos juízes de primeira instância 14.978 .709 processos e, pelos órgãos de 2a instância, 3.494.965 de processos.

Esses milhões de processos julgados sob o regime de metas não melhoraram a rapidez do processo. No mesmo ano de 2013, ingressaram em primeira instância 17.271.369 processos: mais de dois milhões a mais do que os julgados (BRASIL, 2014, passim).

\section{Grandes litigantes e direitos violados}

A insuficiência da preocupação meramente gerencial a respeito do Judiciário brasileiro, enquanto instrumento de efetivação de direitos socialmente conquistados sob um processo democrático, revela-se, portanto, de forma cristalina.

É preciso questionar os motivos pelos quais tantas demandas são ajuizadas anualmente; é necessário perguntar os motivos pelos quais os cidadãos tanto procuram o Judiciário; é preciso, em suma, verificar os fundamentos da explosão da litigiosidade brasileira.

A resposta pode ser avistada a partir dos números divulgados pelo próprio $\mathrm{CNJ}$.

Nos últimos anos, teve-se a circulação de quase 100 (cem) milhões de processos no Judiciário. Trata-se de volume que, sob uma análise mais superficial, enseja a conclusão de uma suposta média de um processo por brasileiro (levando em conta que cada processo envolve, via de regra, no mínimo duas pessoas).

Os dados do CNJ (BRASIL, 2014, passim) elidem, contudo, tal conclusão. Nem todo brasileiro é parte em um processo judicial; na verdade, há brasileiros - ou não brasileiros - que participam mais de processos do que outros.

Existe no Brasil uma categoria conhecida como grandes litigantes. No ano 2011, por exemplo, $38 \%$ dos processos envolviam o setor público federal; $8 \%$ o estadual; $5 \%$ o municipal. Vale dizer, $51 \%$ dos processos apresentavam como parte os entes federativos brasileiros, suas autarquias e empresas públicas; o Estado brasileiro, em suma.

Existem outros dados reveladores: $38 \%$ das ações envolvem bancos e $6 \%$ telefonia. Outros litigantes, como, por exemplo, inquilino contra locador, vizinho contra vizinho, empresas privadas que discutem cláusulas contratuais etc somam, ao todo, apenas 5\% de todos os processos.

Tais números, portanto, confirmam o que já se disse. A explosão da litigiosidade brasileira está relacionada à distância existente entre a realidade das normas e a realidade da vida. 
Não por outro motivo, aquele que detém o papel primordial de efetivar direitos (o Estado) e as duas categorias de empresas que representam o capitalismo globalizado deste início de século XXI são os que abarrotam o Judiciário de processos. Eis os grandes violadores dos direitos conquistados pela mobilização social.

\section{Judiciário e Poder Administrativo}

No reconhecimento da democracia enquanto processo eminentemente contraditório, Lefort (2011, p. 91) chama a atenção para um verdadeiro fantasma a assombrar os sistemas democráticos: o Poder Administrativo. Trata-se de uma força oriunda da complexidade dos problemas vivenciados pelas sociedades contemporâneas, fomentando a burocracia interna e tomando, como um problema burocrático, questões que deveriam ser debatidas e demandadas politicamente pela sociedade civil.

Nas últimas décadas, o advento do chamado neoliberalismo tem ensejado o crescimento desse Poder Administrativo.

Advirta-se que quando se fala em neoliberalismo não se fala necessariamente de Estado Mínimo, como seus defensores costumam afirmar ${ }^{5}$. Fala-se de Estado ocupado e dominado pelo mercado que, por um lado, leva ao enfraquecimento da promoção do bemestar social, mas, de outro lado, segundo Boaventura de Sousa Santos (2002, p. 154), não enseja o abalo do peso burocrático que "[...] faz com que ao enfraquecimento e ineficácia da administração pública venha juntar-se o crescente autoritarismo de um sem-número de burocracias desajustadas, cada uma exercendo o seu micro-despotismo sobre cidadãos cada vez mais impotentes e politicamente incapazes".

Ora, o individualismo do mercado é incapaz de enxergar o Estado como o responsável pela efetivação dos direitos. Nas palavras do próprio Lefort (2000, p. 2), a globalização neoliberal relegou "[...] ao segundo plano o papel dos estados e, de um modo geral, da ação política".

Para o mercado, ao aparelho estatal não cabe exercer o trabalho de mediador das mudanças que "[...] surgem por iniciativa própria dos mais diversos setores da sociedade" (ROCHA, 2011, p. 46). Sob tal raciocínio, cabe ao Estado manter basicamente a ordem, a estabilidade e a previsibilidade imprescindível para a expansão do capital, o que não se coaduna com a democracia enquanto processo histórico, onde, nas palavras de Lefort:

[...] o poder, a lei, o conhecimento se encontram postos à prova de uma indeterminação radical, sociedade que se tornou teatro de uma aventura

\footnotetext{
5 É de se lembrar que: "O capitalismo - repita-se - reclama não o afastamento do Estado dos mercados, mas sim a atuação estatal reguladora, a serviço dos interesses do mercado” (GRAU, 2014, p. 133).
} 
indomesticável, tal que o que se vê instituído não está nunca estabelecido, o conhecido permanece minado pelo desconhecido, o presente se revela inominável, cobrindo tempos sociais múltiplos não sincronizados uns com relação aos outros na simultaneidade - ou nomeáveis apenas na ficção do futuro; uma aventura tal que a procura da identidade não se desfaz da experiência da divisão. (2001, p. 151)

A reforma implementada no Judiciário brasileiro não visou aos direitos reconhecidos pelo Estado a partir de mobilizações oriundas do poder social. Nada se fez para solucionar o quadro de violação de direitos evidenciado pela existência dos grandes litigantes, a ocupar cerca de $95 \%$ dos processos ora judicialmente em trâmite.

O que se pretendeu fazer foi garantir estabilidade, tratando os membros do Judiciário como agentes de mercado detentores da responsabilidade de cumprir metas. Instrumentalizou-se a atividade jurisdicional para se retirar o caráter político dos direitos, burocratizando-os.

Não se está a negar a importância do CNJ como instrumento de controle e de transparência sobre um poder até então destituído de qualquer fiscalização não corporativa. Os próprios números relativos ao Judiciário (processos em trâmite, processos julgados, grandes litigantes), mencionados no presente texto, somente são conhecidos em razão do próprio órgão de controle externo.

O problema encontra-se na insuficiência democrática do $\mathrm{CNJ}$ e de sua função eminentemente gerencial. $O$ controle externo tem-se revelado como uma adaptação do autoritarismo do Judiciário para os novos tempos: supera-se o totalitarismo dos militares em favor do totalitarismo mercadológico, ou mais precisamente, o totalitarismo neoliberal, via Poder Administrativo.

\section{Observações finais}

Analisando a obra de Lefort, anota André Rocha que:

A distinção entre poder político e o poder administrativo, por outro lado, permite pensar certos mecanismos de exclusão política ainda operantes nos regimes democráticos e que, portanto, consistem em corrosivos germes do totalitarismo: a especialização técnicoadministrativa tende a produzir uma casta de especialistas que são apresentados, segundo a ideologia da competência, como os únicos capazes de resolver certos problemas sociais e políticos. E o pior: os políticos podem se tornar tecnocratas que se apresentam como os únicos 
capazes de agir na política, e os intelectuais podem se tornar politólogos que se apresentam como os únicos competentes para pensar e dizer a política. (2011, p. 48)

A crescente burocratização da atividade jurisdicional visando à ordem acima das mobilizações e dos direitos, somada à anacrônica estruturação deste poder de Estado conforme construção da ditadura civil-militar pós-1964, parecem autenticar o arcabouço do Judiciário como verdadeiro germe do totalitarismo presente no Brasil regido democraticamente pela Constituição Federal de 1988.

Sabe-se que, nos dias atuais, o país sofre temível recrudescimento conservador. Da defendida terceirização das relações de trabalho a desmobilizar sindicatos à igualmente defendida legislação antiterrorista a considerar a mobilização social como ação criminosa, enxerga-se um claro movimento de crescimento do aparelho repressor e, por consequência, de "[...] anulação dos sinais da divisão do Estado e da sociedade e da divisão social interna" (LEFORT, 2011, p. 98).

Em tal quadro, o que se esperaria de uma sociedade democrática seria um Judiciário a atuar como garantidor dos direitos oriundos da mobilização social, inclusive colocando freios a arroubos autoritários oriundos do Executivo e do Legislativo. Todavia, sob uma atividade jurisdicional cada vez mais burocratizada e regida pela eficiência mercadológica, não se pode dela esperar muito mais senão uma força legitimadora do enfraquecimento de uma democracia recém-inventada.

\section{BRAZILIAN DEMOCRATIC INVENTION AND TOTALITARIAN GHOSTS: THE CASE OF JUDICIAL POWER APPLIED TO THE WORK OF CLAUDE LEFORT}

Abstract: The Claude Lefort's ideas are applicable to brazilian reality after the Decade of 1980 . This is the matching period to a broad democratic invention process: it was a product of social mobilization whose political flags turned into rights provided in the Constitution of 1988. On the other hand, the society failed to eliminate old dictatorial structures and to does not prevent the growth of an administrative power politically. This is what happens in the Brazilian Judiciary, that is sought for the population to commit rights, but it is still structured dictatorially and subjected to reforms that extend the administrative power under the pretext of ensuring legal certainty. The present work intends to relate the ideas of Lefort to the current context of strengthening authoritarian structures in the Judiciary, under the term of the democratic Constitution.

Keywords: Claude Lefort - democracy - judicial power - constitution - authoritarianism.

\section{Referências bibliográficas}

BAXI, U. Politics of reading human rights: Inclusion and exclusion within the production of human rights. In: SALADIN, MECKELED-GARCÍA, Saladin; ÇALI, Basak (org.). The 
Legalization of Human Rights: Multidisciplinary Perspectives on Human Rights and Human Rights Law (ebook). New York: Routledge, 2006.

BRASIL. Justiça em números. Brasília: Conselho Nacional de Justiça, 2014. Disponível em: <ftp://ftp.cnj.jus.br/Justica_em_Numeros/relatorio_jn2014.pdf>.

CHAUÍ, M. Apresentação. In: LEFORT, Claude. A invenção democrática: os limites da dominação totalitária. $3^{a}$ ed. Belo Horizonte: Autêntica, 2011, pp. 37-41.

DONNELLY, J. The Virtues of Legalization. In: MECKELED-GARCÍA, Saladin; ÇALI, Basak (org.). The Legalization of Human Rights: Multidisciplinary Perspectives on Human Rights and Human Rights Law (ebook). New York: Routledge, 2006.

FERNANDES, F. A Constituição como projeto político. Tempo Social: Revista de Sociologia da USP. São Paulo: Universidade de São Paulo, 1989, pp. 47-55.

FONSECA, F. O consenso forjado: a grande imprensa e a formação da agenda ultraliberal no Brasil. São Paulo: Hucitec, 2005.

GRAU, E. R. O direito posto e o direito pressuposto. $9^{\mathrm{a}}$ ed. São Paulo: Malheiros, 2014.

LEFORT, C. O direito internacional, os direitos do homem e a ação política. Tempo social: Revista de Sociologia da USP, São Paulo, maio 2000, pp. 1-10. A invenção democrática: os limites da dominação totalitária. $3^{\mathrm{a}}$ ed. Belo Horizonte: Autêntica, 2011.

MICHILES, C., e outros. Cidadão constituinte: a saga das emendas populares. Rio de Janeiro: Paz e Terra, 1989.

ROCHA, A. Introdução - dialética e democracia. In: LEFORT, Claude. A invenção democrática: os limites da dominação totalitária. $3^{a}$ ed. Belo Horizonte: Autêntica, 2011. pp. 43-55.

SANTOS, B. S. Introdução à sociologia da administração da justiça. Revista crítica de ciências sociais, n. 21. Coimbra, nov. 1986.

SOUZA, H. J. A Constituinte se curva ao capital. In: MICHILES, C., e outros. Cidadão constituinte: a saga das emendas populares. Rio de Janeiro: Paz e Terra, 1989, pp. 375-378. 